\title{
Can intractable discogenic back pain be managed by low-level laser therapy without recourse to operative intervention?
}

This article was published in the following Dove Press journal:

Journal of Pain Research

26 May 2015

Number of times this article has been viewed

\author{
David IP \\ Nga-Yue Fu \\ Asia Medical Pain Centre, Mong \\ Kok, Hong Kong, People's Republic \\ of China
}

Objective: The aim of the study reported here was to investigate the possible clinical role of low-level laser therapy (LLLT) in discogenic back pain patients who failed to respond to a conventional physical therapy program to avoid recourse to operative intervention.

Methods: The paper reports on the long-term mean 5-year prospective follow-up of a patient cohort of 50 unselected patients visiting our tertiary referral pain center for discogenic back pain who had had a single-level lesion documented by magnetic resonance imaging followed by subsequent discography to confirm the affected disc being the pain generator. All of the patients who entered the study had failed response to a combination of nonsteroidal anti-inflammatory agents and had had not less than 3 months of conventional physical therapy. LLLT, at a wavelength of $810 \mathrm{~nm}$ wavelength emitted from a GaAIAs semiconductor laser device with $5.4 \mathrm{~J}$ per point and a power density of $20 \mathrm{~mW} / \mathrm{cm}^{2}$, was employed. The treatment regimen consisted of three sessions of treatment per week for 12 consecutive weeks.

Results: All but one patient had significant improvement in their Oswestry Disability Index score, from a mean of $50 \%$ score to a mean of $10 \%$ score, at the end of treatment at 12 weeks. In addition, surprisingly, the improvement was found maintained at follow-up assessments 1 year and 5 years later. The one patient among the 50 patients who failed to respond eventually required surgery, while the others did not require surgery.

Conclusion: We conclude that LLLT is a viable option in the conservative treatment of discogenic back pain, with a positive clinical result of more than $90 \%$ efficacy, not only in the short-term but also in the long-term, with lasting benefits.

Keywords: GaAIAs semiconductor laser, Oswestry Disability Index, single-level lesion, LLLT

\section{Introduction}

The significance of low-level laser in clinical medicine began with the important works of Endre Mester. In recent years, the various clinical applications of low-level laser therapy (LLLT) have mainly been based on previous scientific works concerning the effect of low-level lasers, which exert a positive influence on fibroblast ${ }^{1}$ and collagen synthesis $^{2}$ at the cellular-molecular level.

As far as discogenic back pain is concerned, most orthopedic surgeons use nonsteroidal anti-inflammatory medications and conventional physical therapy consisting of ultrasonic therapy, traction therapy, trans-cutaneous electrical therapy, and short-wave therapy. These forms of conservative treatment modalities represent symptomatic treatment only, without the biomodulation effects offered by low-level lasers; for instance, ultrasound treatment affords neither anti-inflammatory nor biomodulation effects at the cellular-molecular level.
Correspondence: David IP

Asia Medical Pain Centre, 4/F Tower

2 Grand Plaza, Mong Kok, Hong Kong,

People's Republic of China

Tel +852 23880389

Email ipdavid@hotmail.com.hk 
Although there have been numerous clinical studies on the use of LLLT in various forms of arthritis, there is a relative paucity of clinical studies of LLLT on discogenic back pain. The objective of this paper is to report the clinical result of a study on the efficacy of LLLT therapy in the management of discogenic back pain.

\section{Materials and methods}

The study population consisted of a series of consecutive unselected 50 patients with documented one-level discogenic back pain, with a prior discogram confirming the abnormal level - as seen by magnetic resonance imaging - being the pain generator. The research represents a prospective cohort study into whether LLLT therapy has any clinical efficacy in managing discogenic back pain and, if so, whether the benefit is short-term or long-term. Exclusion criteria included patients presenting as late as more than 6 months after disease onset, as centralization of pain may have occurred in such situations; patients above age 60 years; and patients who had concomitant other spinal pathologies on magnetic resonance imaging, such as degenerative facet joints or spondylolisthesis. In addition, patients with prior spinal operations were excluded, as were subjects who had potential contraindications for the use of laser treatment, such as a previous history of tumor, ongoing sepsis, or pregnancy.

All patients signed informed consent detailing that they would be treated by LLLT and that only US Food and Drug Administration-approved devices would be used.

Figure 1 is a flowchart of the patient selection process for the current study.

Each subject was clinically examined and followed up by the same orthopedic surgeon to minimize interobserver error.

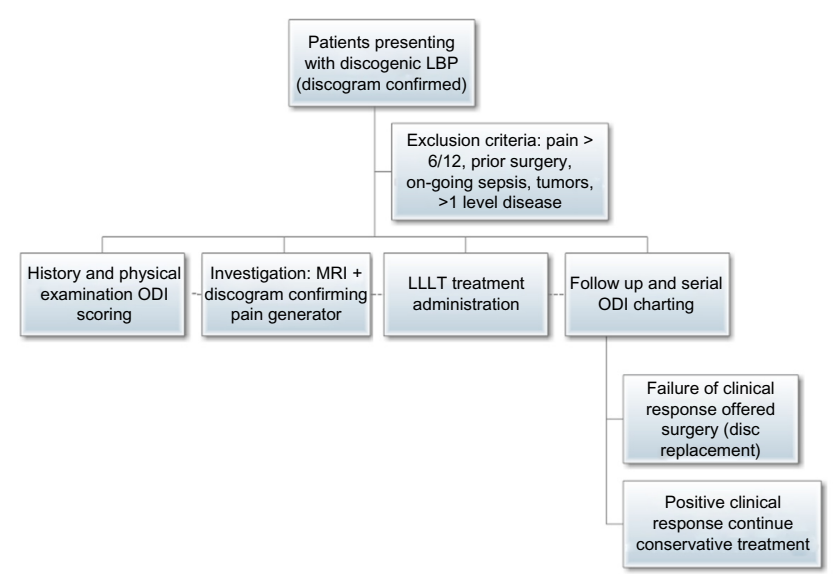

Figure I Flowchart of the patient selection process.

Abbreviations: LBP, lower back pain; LLLT, low-level laser therapy; MRI, magnetic resonance imaging; ODI, Oswestry Disability Index.
All the low-level laser pain treatments were also performed by the same orthopedic surgeon. During the initial visit, extra care was taken to document the spinal range of motion, presence of neurological deficit, sites of tenderness, and presence of spinal deformity. We employed the well-known and validated Oswestry Disability Index (ODI) to score the level of disability in the initial and all subsequent follow-ups in the ensuing years. The ODI assesses aspects including: pain intensity, personal care, lifting, walking, sitting, standing, sleeping, social and sex life, and ambulation ability. A score of $0 \%-20 \%$ represents minimal disability, $21 \%-40 \%$ represents moderate disability, $41 \%-60 \%$ severe disability, $61 \%-80 \%$ crippled, and $81 \%-100 \%$ bed bound.

LLLT of a wavelength of $810 \mathrm{~nm}$ emitted from a GaAIAs semiconductor laser device, with $5.4 \mathrm{~J}$ per point and a power density $20 \mathrm{~mW} / \mathrm{cm}^{2}$, was employed. The treatment regimen consisted of three sessions of treatment per week for 12 consecutive weeks. Each treatment session lasted 180 seconds. Figure 2 shows a patient receiving laser treatment for discogenic back pain. Protective laser eye goggles were provided to both the patient and the clinician. We did not add on any other conventional therapy during each treatment session, as all the subjects had had these therapeutic interventions before but had failed to respond. No medications were prescribed to the subjects under study, as all of these patients had also failed to respond to oral anti-inflammatory agents provided by other clinicians before receiving treatment at our tertiary referral pain center.

\section{Results}

The mean age of the 50 subjects was 45 (range: 36-57) years, all having had one-level disc disease documented by prior discography injection to confirm that the affected disc was the

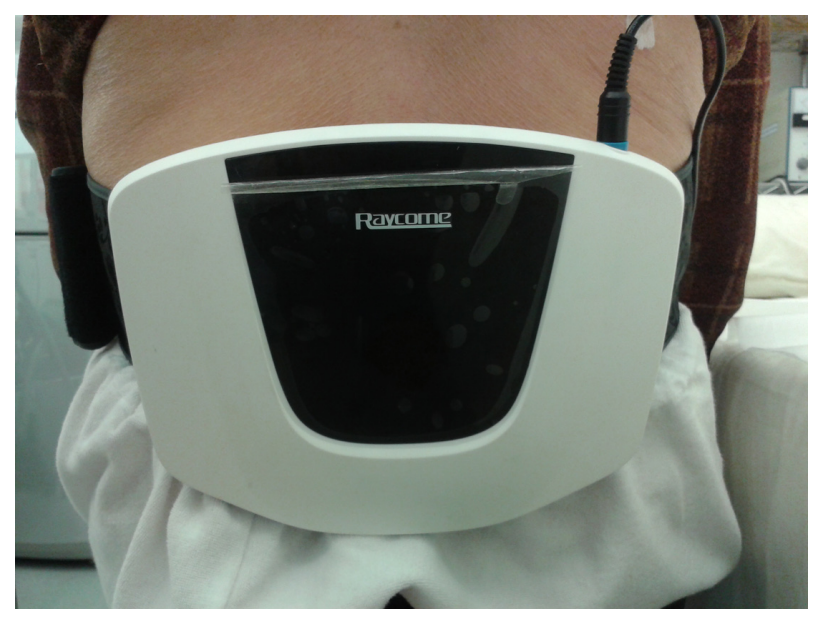

Figure 2 A patient receiving laser treatment for discogenic back pain. 
pain generator. The L5/S1 level was the level affected in $60 \%$ of subjects, while the others had L4/5-level disc disease. The male to female ratio was 1.5:1.0. The study period lasted from 2008 to the end of 2014. Upon entry to the study, if the subject had had their last magnetic resonance imaging more than 1 year ago, a new set of images were taken to ensure there were no newer undetected pathologies that may affect the result of treatment, such as multilevel disc pathology.

All 50 subjects in the study population completed the treatment regimen with good compliance; there were no defaults. Neither side effects nor any patient discomfort were documented during any treatment. Only one patient failed to positively respond to the laser treatment and eventually required surgery; however, even this patient's ODI score was reduced by $10 \%$ after treatment, making her more comfortable while awaiting for inter-vertebral disc replacement surgery.

For the remaining 49 patients, there was a statistically significant reduction in ODI score, from a mean of $50 \%$ at the commencement of the study (range: $45 \%-55 \%$ ) with a standard deviation of 3.8 to a mean of $10 \%$ at the end of treatment after 12 weeks (range: $5 \%-15 \%$ ) with a standard deviation of 3.9 with an outlier which represents the nonresponder. The improvement was found maintained at the 1-year follow-up, with the mean ODI score being $10 \%$ (range: $5 \%-15 \%$ ) and even at the 5-year follow-up, when the mean ODI score remained at a satisfactory level of $15 \%$ (range: $10 \%-20 \%$ ). In this study, the mean was used instead of the median, as analysis of the data revealed near normal distribution. Table 1 summarizes the pre- and posttreatment ODI scores of the patients and includes their demographic details. Statistical significance was confirmed using Student's $t$-test, wherein the marked difference in the pre- and posttreatment ODI scores after LLLT rejected the null hypothesis that the difference could have occurred by chance, with a $P$-value $<0.05$.

The mean clinical follow-up of this patient cohort was 5 years (range: $4.5-6.0$ years). A reasonably long follow-up was required to reveal whether LLLT therapy alone could provide any lasting benefits in patients, as well as any incipient side effects. In this study, no side effect was observed and there was no discomfort felt by patients during therapy.

\section{Discussion}

Over the past years, more than 100 double-blind placebocontrolled studies have been published on the effects of LLLT. These articles also showed the favorable anti-inflammatory effect of LLLT. ${ }^{3-5}$ However, despite the fact that there have
Table I Patient Demographics, Pre- and Post-LLLT ODI Scores

\begin{tabular}{|c|c|c|c|}
\hline $\begin{array}{l}\text { Patient's } \\
\text { Age/Sex }\end{array}$ & $\begin{array}{l}\text { Disc } \\
\text { Affected }\end{array}$ & $\begin{array}{l}\text { Pre-Rx } \\
\text { ODI (\%) }\end{array}$ & $\begin{array}{c}\text { Post-Rx } \\
\text { ODI (\%) }\end{array}$ \\
\hline Male 57 & L5/SI & 55 & 15 \\
\hline Female 52 & $\mathrm{~L} 4 / 5$ & 50 & 10 \\
\hline Female 4I & $\mathrm{L} 4 / 5$ & 45 & 5 \\
\hline Male 46 & L5/SI & 50 & 10 \\
\hline Female 38 & L5/SI & 50 & 10 \\
\hline Male 39 & L4/5 & 45 & 5 \\
\hline Male 43 & L4/5 & 55 & 15 \\
\hline Male 38 & L5/SI & 45 & 10 \\
\hline Female 42 & L5/SI & 55 & 10 \\
\hline Female 37 & $\llcorner 4 / 5$ & 45 & 5 \\
\hline Male 46 & $\mathrm{~L} 4 / 5$ & 50 & 10 \\
\hline Female 48 & L5/SI & 50 & 15 \\
\hline Male 44 & $\llcorner 4 / 5$ & 55 & 15 \\
\hline Male 43 & L5/SI & 45 & 10 \\
\hline Female 44 & $\llcorner 4 / 5$ & 50 & 10 \\
\hline Male 4I & L5/SI & 45 & 15 \\
\hline Male 44 & L5/SI & 50 & 10 \\
\hline Female 39 & L5/SI & 45 & 5 \\
\hline Female 47 & L5/SI & 50 & 15 \\
\hline Male 4I & $\mathrm{L} 4 / 5$ & 45 & 5 \\
\hline Male 39 & L5/SI & 50 & 5 \\
\hline Female 43 & L4/5 & 50 & 10 \\
\hline Male 42 & L5/SI & 55 & 5 \\
\hline Male 38 & L5/SI & 45 & 5 \\
\hline Female 39 & L5/SI & 50 & 10 \\
\hline Female 45 & $\llcorner 4 / 5$ & 50 & 15 \\
\hline Male 40 & $\llcorner 4 / 5$ & 45 & 5 \\
\hline Male 46 & L5/SI & 50 & 15 \\
\hline Male 47 & L5/SI & 55 & 10 \\
\hline Female 47 & L4/5 & 50 & 45 \\
\hline Male 45 & L5/SI & 45 & 10 \\
\hline Female 45 & $\mathrm{~L} 4 / 5$ & 50 & 5 \\
\hline Male 48 & L5/SI & 45 & 15 \\
\hline Female 49 & L5/SI & 50 & 10 \\
\hline Male 50 & L5/SI & 55 & 15 \\
\hline Male 45 & $\mathrm{~L} 4 / 5$ & 50 & 5 \\
\hline Male 50 & $\mathrm{~L} 4 / 5$ & 45 & 10 \\
\hline Female 5I & $\llcorner 4 / 5$ & 50 & 15 \\
\hline Male 46 & L5/SI & 45 & 5 \\
\hline Male 45 & L5/SI & 50 & 5 \\
\hline Female 49 & L5/SI & 55 & 15 \\
\hline Male 48 & $\mathrm{~L} 4 / 5$ & 45 & 10 \\
\hline Female 47 & L5/SI & 50 & 10 \\
\hline Male 46 & L5/SI & 45 & 5 \\
\hline Male 48 & L5/SI & 55 & 15 \\
\hline Female 49 & L5/SI & 50 & 10 \\
\hline Male 50 & L5/SI & 55 & 15 \\
\hline Male 45 & L5/SI & 45 & 5 \\
\hline Female 47 & $\mathrm{~L} 4 / 5$ & 55 & 15 \\
\hline Male 45 & $\llcorner 4 / 5$ & 45 & 5 \\
\hline
\end{tabular}

Abbreviations: ODI, Oswestry Disability Index; Rx, prescription.

been many published studies on LLLT in the treatment of painful peripheral joints, there is a relative paucity of studies on discogenic back pain, aside from the double-blind controlled study on acute back pain with radiculopathy 
published by Konstantinovic et al. ${ }^{6}$ One recent study by Malliapoulos et $\mathrm{al}^{7}$ confirmed the short-term efficacy of LLLT in treating discogenic back pain, but there was no mention that the researchers had confirmed prior to commencement of the study that the affected disc was the pain generator in each case. $\mathrm{Ip}^{8}$ previously pointed out that there is more medical literature on the treatment of painful peripheral joints with LLLT than on its treatment of back pain, thus patients are sometimes being subjected to unnecessary disc surgery, such as intra-discal heating, radiofrequency treatment for dorsal root ganglion, or open procedures like disc replacement or even spinal fusion.

Traditional treatments of painful discogenic back pain syndrome involve nonsteroidal anti-inflammatory agents as well as conventional physiotherapy such as ultrasound therapy and electrical stimulation therapy. None of these therapies confers the biomodulation effects that LLLT does, such as improvement in microcirculation or the upregulation of several genes involved in energy metabolism and oxidative phosphorylation, which stimulates an increase in adenosine triphosphate production, which in turn regulates other cellular processes and leads to the normalization of biological functions at the cellular level. ${ }^{9}$ This is in sharp contrast to the biophysical effects of therapeutic ultrasound devices that do not even have anti-inflammatory effects let alone biomodulation effects. ${ }^{10}$ In general, for any conservative treatment for discogenic back pain to be meaningful, the treatment modality must have lasting effects and benefits for the patient, rather than providing transient pain relief, such as the administration of painkillers does. We are not aware of any clinical study reporting on the long-term efficacy of LLLT in the management of back pain. In the study reported here, LLLT showed evidence of lasting benefit and represents a viable option to surgery.

\section{Conclusion}

In the prospective study reported here of a patient cohort of 50 patients with documented single-level discogenic back pain, a significant positive clinical response of patients to LLLT was demonstrated, as evidenced by the marked lowering of patients' ODI scores - not only in the short-term but also in the long-term, as the mean clinical follow-up in this prospective study was 5 years.

Further large-scale studies will be worthwhile to further explore the use of LLLT, not only in the treatment of discogenic back pain but also in other painful orthopedic conditions.

\section{Disclosure}

The authors declare no conflicts of interest in this work.

\section{References}

1. van Breugel HH, Bär PR. Power density and exposure time of $\mathrm{He}-\mathrm{Ne}$ laser irradiation are more important than total energy dose in photo-biomodulation of human fibroblasts in vitro. Lasers Surg Med. 1992;12(5):528-537.

2. Lam TS, Abergel RP, Meeker CA, Castel JC, Dwyer RM, Uitto J. Laser stimulation of collagen synthesis in human skin fibroblast cultures. Lasers Life Sci. 1986;1:61-77.

3. Bjordal JM, Johnson MI, Iversen V, Aimbire F, Lopes-Martins RA. Low-level laser therapy in acute pain: a systematic review of possible mechanisms of action and clinical effects in randomized placebocontrolled trials. Photomed Laser Surg. 2006;24(2):158-168.

4. Bjordal JM, Lopes-Martins RA, Iversen VV. A randomised, placebo controlled trial of low level laser therapy for activated Achilles tendinitis with microdialysis measurement of peritendinous prostaglandin E2 concentrations. Br J Sports Med. 2006;40(1):76-80.

5. Castano AP, Dai T, Yaroslavsky I, et al. Low-level laser therapy for zymosan-induced arthritis in rats: Importance of illumination time. Lasers Surg Med. 2007;39(6):543-550.

6. Konstantinovic LM, Kanjuh ZM, Milovanovic AN, et al. Acute low back pain with radiculopathy: a double-blind, randomized, placebocontrolled study. Photomed Laser Surg. 2010;28:553-560.

7. Malliapoulos N, Akritidou A, et al. Low-level laser therapy (LLLT) for discogenic back pain. Br J Sports Med. 2011;45;e1.

8. Ip D. Orthopedic Rehabilitation, Assessment, and Enablement. Heidelberg: Springer-Verlag; 2007: Chapter 16.

9. Hashmi JT, Huang YY, Osmani BZ, Sharma SK, Naeser MA, Hamblin MR. Role of low-level laser therapy in neurorehabilitation. PM R. 2010;2(12 Suppl 2):S292-S305.

10. Baker KG, Robertson VJ, Duck FA. A review of therapeutic ultrasound: biophysical effects. Phys Ther. 2001;81(7):1351-1358.
Journal of Pain Research

\section{Publish your work in this journal}

The Journal of Pain Research is an international, peer-reviewed, open access, online journal that welcomes laboratory and clinical findings in the fields of pain research and the prevention and management of pain. Original research, reviews, symposium reports, hypothesis formation and commentaries are all considered for publication.

\section{Dovepress}

The manuscript management system is completely online and includes a very quick and fair peer-review system, which is all easy to use. Visit http://www.dovepress.com/testimonials.php to read real quotes from published authors. 